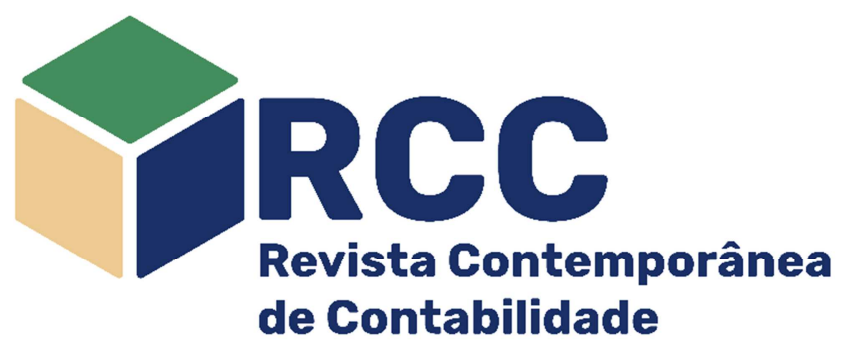

\title{
Volatilidade do fluxo de caixa e da disponibilidade de caixa na estrutura de capital de empresas industriais brasileiras
}

\author{
The volatility of cash flow and cash availability in the capital structure of Brazilian industrial \\ companies
}

Volatilidad del flujo de caja y de la disponibilidad de caja en la estructura de capital de las empresas industriales brasileñas

Edgar Pamplona*

Doutor em Ciências Contábeis e Administração (FURB)

Professor do Departamento de Ciências Contábeis, Campus de Três Lagoas (UFMS), Três Lagoas/MS, Brasil edgar.pamplona@ufms.br https://orcid.org/0000-0002-2579-5458

Tarcísio Pedro da Silva Doutor em Ciências Contábeis e Administração (FURB) Professor do Programa de Pós-Graduação em Ciências Contábeis (FURB), Blumenau/SC, Brasi tarcisio@furb.br https://orcid.org/0000-0002-2370-791X (i)
Cristiane Canton Mestra em Ciências Contábeis (FURB), Blumenau/SC, Brasil cantoncristiane@gmail.com https://orcid.org/0000-0002-4074-435X

Moacir Manoel Rodrigues Junior Doutor em Métodos Numéricos em Engenharia (UFPR) Professor do Programa de Pós-Graduação em Ciências Contábeis (FURB), Blumenau/SC, Brasil mmrodrigues@furb.br https://orcid.org/0000-0003-0309-3604 (1)

Endereço do contato principal para correspondência* Rua dos Maçons, 427 - Casa 2 - Bairro Quinta da Lagoa, CEP: 79.611-130, Três Lagoas/MS, Brasil

\section{Resumo}

Este estudo tem por objetivo verificar o efeito da volatilidade do fluxo de caixa e da volatilidade da disponibilidade de caixa na estrutura de capital de empresas industriais brasileiras. Desenvolveu-se pesquisa descritiva, documental e quantitativa. A amostra abrangeu 77 empresas industriais brasileiras listadas na Brasil, Bolsa, Balcão (B3), com dados de 2014 a 2018 e que geraram, ao todo, 385 observações. As informações econômico-financeiras foram extraídas da base Economática $\AA^{\circledR}$. Os resultados apontam que empresas com maior Volatilidade do Fluxo de Caixa (VFC) e maior Volatilidade da Disponibilidade de Caixa (VDC) apresentam patamares de endividamento superiores, sendo estas também mais extensivas no curto prazo. Ademais, como diferencial metodológico, observou-se que quando a Volatilidade do Fluxo de Caixa deriva de tendência positiva, conforme crescimento dos fluxos gerados nos últimos períodos, credores tendem a observar isto de forma favorável e ceder mais recursos a empresas nestas condições, inclusive com maior prazo para pagamento.

Palavras-chave: Volatilidade do fluxo de caixa; Volatilidade da disponibilidade de caixa; Estrutura de capital

\section{Abstract}

This study aims to verify the effect of cash flow volatility and cash availability volatility on the capital structure of Brazilian industrial companies. Descriptive, documentary, and quantitative research were developed. The sample included 77 Brazilian industrial companies listed in Brasil, Bolsa, Balcão (B3), with data from 2014 to 2018, which generated a total of 385 observations. The economic and financial information was extracted from the Economática ${ }^{\circledR}$ database. The results show that companies with greater Cash Flow Volatility (CFV) and greater Cash Availability Volatility (CAV) have higher indebtedness levels, which are also more extensive in the short term. Furthermore, as a methodological difference, it was observed that when the Cash Flow Volatility derives from a positive trend, according to the growth of flows generated in recent periods, creditors tend to observe this favorably and provide more resources to companies under these conditions, including a longer-term for payment.

Keywords: Cash flow volatility; Cash availability volatility; Capital structure 


\section{Resumen}

Este estudio tiene como objetivo verificar el efecto de la volatilidad del flujo de caja y la volatilidad de la disponibilidad de caja en la estructura de capital de las empresas industriales brasileñas. Se desarrolló una investigación descriptiva, documental y cuantitativa. La muestra incluyó 77 empresas industriales brasileñas listadas en Brasil, Bolsa, Balcão (B3), con datos de 2014 a 2018 y que generaron, en total, 385 observaciones. La información económico-financiera se extrajo de la base Economática $\AA^{\circledR}$. Los resultados muestran que las empresas con mayor Volatilidad del Flujo de Caja (VFC) y mayor Volatilidad de la Disponibilidad de Caja (VDC) tienen mayores niveles de endeudamiento, siendo también más extensos en el corto plazo. Además, como diferencial metodológico, se observó que cuando la VFC se deriva de una tendencia positiva, como los flujos generados en los últimos períodos han crecido, los acreedores tienden a observar esto de manera favorable y a conceder aún más recursos a las empresas en estas condiciones, y también con un plazo más largo para el pago.

Palabras clave: Volatilidad del flujo de caja; Volatilidad de la disponibilidad de caja; Estructura de capital

\section{Introdução}

Estrutura de capital é definida como o meio pelo qual uma organização é financiada, que compreende a relação entre dívida e capital próprio (Muritala, 2012). Esse tema tem sido uma das questões centrais nas pesquisas em finanças desde trabalhos seminais do final da década de 1950 e início da década de 1960, com especial atenção a Modigliani e Miller (1958) e a Modigliani e Miller (1963). De fato, a forma como uma empresa é financiada é fundamental para inúmeros interessados, como gestores e acionistas, visto que a incorreta combinação das fontes de financiamento tende a afetar severamente o desempenho e a sobrevivência das empresas (Muritala, 2012). Frente a este cenário, ao longo do tempo, teorias foram desenvolvidas visando compreender a forma como as organizações estruturam suas fontes de financiamento, sendo o nível ideal de dívida o aspecto central de discussão.

De acordo com Cai, Fairchild e Guney (2008), adicionalmente ao nível de endividamento, outro aspecto de importante observância é a maturidade da dívida. A escolha da dívida entre curto prazo e longo prazo traz intrínsecas diversas consequências relevantes. Tem-se que a estrutura de passivos da empresa deve estar alinhada à sua estrutura de ativos, a fim de evitar possíveis liquidações corporativas. Além disso, as empresas podem sinalizar seus lucros escolhendo um mix de maturidade da dívida específico, visto que esta tende a afetar o custo do financiamento corporativo.

Neste sentido, inúmeros pesquisadores em finanças têm se direcionado a compreender quais fatores afetam a forma como as organizações captam seus recursos. Apesar dos avanços existentes nesta temática, diante de resultados diversificados, vários pontos permanecem inconclusivos. Numa visão contemporânea, Memon, Chen, Tauni e Ali (2018) mencionam que um dos fatores que afetam as decisões dos gerentes financeiros em relação à política de estrutura de capital é a volatilidade do fluxo de caixa. Todavia, mesmo com crescente interesse acerca do referido fenômeno, Keefe e Yaghoubi (2016) e Memon et al. (2018) ressaltam que a literatura empírica é inconclusiva.

No campo teórico, a influência da volatilidade do fluxo de caixa no nível de dívida é entendida como negativa, uma vez que à medida que cresce a volatilidade, as chances de uma organização enfrentar dificuldades financeiras também se elevam e, como resultado, diminui o valor das vantagens fiscais da dívida. Logo, as empresas que enfrentam alta volatilidade do fluxo de caixa diminuem seus níveis de alavancagem para que possam minimizar o custo da dívida (Memon et al., 2018). Já em referência a maturidade da dívida, para Dangl e Zechner (2016), a alta volatilidade do fluxo de caixa reduz o prazo da dívida (Dangl e Zechner, 2016) e, assim, espera-se que empresas com alta (baixa) volatilidade do fluxo de caixa usem dívidas com vencimentos curtos (longos) (Memon et al., 2018).

Por fim, destaca-se que além da volatilidade do fluxo de caixa, buscar-se-á, ainda, testar a volatilidade da disponibilidade de caixa, com vistas a averiguar se à destinação dos fluxos de caixa gerados, quando alocados em caixa e seus equivalentes, também influenciam na forma como as organizações captam recursos. Portanto, diante de todo o cenário descrito, emerge-se o seguinte problema de pesquisa: qual o efeito da volatilidade do fluxo de caixa e da volatilidade da disponibilidade de caixa na estrutura de capital de empresas industriais brasileiras? Para responder à questão delineada, esta pesquisa apresenta como objetivo verificar o efeito da volatilidade do fluxo de caixa e da volatilidade da disponibilidade de caixa na estrutura de capital de empresas industriais brasileiras.

O estudo justifica-se por inúmeras perspectivas. De acordo com Serrasqueiro e Caetano (2015), apesar de incontáveis pesquisas terem sido desenvolvidas ao longo do tempo, não há consenso sobre qual a melhor forma das organizações estruturarem suas fontes de financiamento (Serrasqueiro \& Caetano, 2015) e quais fatores influenciam tais escolhas. Numa perspectiva similar, Tripathy e Asija (2017) mencionam que estrutura de capital continua sendo um dos tópicos mais controversos na literatura financeira. Teorias como a trade-off theory, a pecking-order theory e a market timing theory buscam explicar condicionalmente a escolha do capital corporativo, todavia, as pesquisas ainda não apresentaram uma teoria unificada, deixando o tema aberto para futuros estudos. 
Quanto à volatilidade do fluxo de caixa, estudos internacionais recentes como de Keefe e Yaghoubi (2016) e de Memon et al. (2018) têm sido desenvolvidos buscando compreender como este fator afeta a estrutura de capital das empresas, conotando ser atual em finanças corporativas. Já no Brasil, o estudo da temática é ainda mais recente, se oportunizando em poucos trabalhos, como de Martins e Vasconcelos (2020). Logo, procura-se avançar em dois aspectos principais em relação as pesquisas citadas, sendo: 1) compreender como a volatilidade da disponibilidade de caixa, sendo essa uma medida de destinação do caixa gerado, afeta a forma como as organizações captam seus recursos; e, 2) compreender como a tendência, se crescente ou decrescente, da volatilidade do fluxo de caixa e da volatilidade da disponibilidade de caixa contribui para a explicação do fenômeno observado.

Por fim, a pesquisa justifica-se, ainda, pelo cenário de estudo. De acordo com Benachenhou (2013), os denominados países emergentes, dentre eles o Brasil, caracterizam uma nova geografia econômica e social, que não permite mais negligenciá-los (Benachenhou, 2013). Todavia, apesar deste notório cenário, pesquisas sobre o tema estrutura de capital se concentraram, por muito tempo, em países desenvolvidos. Tal afirmação é suportada por Memon et al. (2018), que especificamente acerca da volatilidade do fluxo de caixa na estrutura da dívida, mencionam que as diferenças institucionais dos países emergentes frente aos desenvolvidos necessitam compreensões adicionais, abrindo possibilidades de pesquisas.

\section{Referencial Teórico}

\subsection{Estrutura de Capital}

A estrutura de capital corporativa se caracteriza pelas fontes de financiamentos que permitem à organização operar, investir e crescer diante dos diversos cenários econômicos (Yaghoubi, 2017). O tema estrutura de capital contempla, juntamente com a política de investimentos e os dividendos, os assuntos mais importantes de finanças, o que culminou, ao longo do tempo, em um número extensivo de pesquisas. Ainda assim, mesmo diante da amplitude de estudos existentes, Tripathy e Asija (2017) mencionam que estrutura de capital permanece como um dos temas mais controversos na literatura financeira. A questão de acadêmicos e profissionais perpassa por descobrir a composição ideal entre dívida e patrimônio corporativo que mantenha a empresa competitiva (Tripathy \& Ajisa, 2017).

De acordo com Muritala (2012), a existência (ou não) da estrutura de capital ideal consiste em uma das questões mais complexas existentes no âmago da temática (Muritala, 2012), o que ocasionou, ao longo do tempo, o desenvolvimento de inúmeras teorias, que perpassam por conceituações diversificadas. Dentre tais teorias, destaque é dado a três delas, a saber: a trade-off theory (Modigliani \& Miller, 1958; Modigliani e Miller, 1963); a pecking-order theory (Myers, 1984); e, a market timing theory (Baker \& Wurgler, 2002).

Ao que pese, a trade-off theory estabelece que a dívida deve ser ponderada mediante custos e benefícios, sendo estes, os mais comuns, de falência e de vantagem fiscal, respectivamente; a peckingorder theory opera pelo entendimento de hierarquia no uso das fontes de financiamento, conforme critério de assimetria informacional, em que se deve iniciar pelo autofinanciamento, perpassando por empréstimos junto à terceiros e finalizando, em última instância, com a emissão de capital; e, por fim, a market timing theory considera que a estrutura de capital corporativa é constituída por janelas de oportunidades que variam no decorrer do tempo, em que se utiliza, quando da necessidade, a fonte de capital mais atrativa, podendo esta variar de acordo com o momento requisitado no mercado.

Neste vasto campo, Chong e Kim (2018) destacam que os estudos empíricos que testam as teorias de estrutura de capital têm apresentado sucessos e fracassos, visto a enorme heterogeneidade observada na estrutura de financiamento das organizações globalmente, não permitindo conclusões. Todavia, a suposição generalizada em muitos destes estudos é que a alavancagem corporativa (como medida de estrutura de capital) é estável ao longo do tempo (Chong \& Kim, 2018), garantindo possibilidades de avanços no conhecimento sobre o tema.

Dois aspectos essenciais que são discutidos nesta pesquisa advêm do nível e da maturidade da dívida corporativa. Numa perspectiva histórica, Leland e Toft (1996) mencionam que a escolha da estrutura de capital das empresas, buscando maximizar o valor mercado, está vinculada ao montante (nível) e ao vencimento (maturidade) da dívida. Numa perspectiva contemporânea, Keefe e Yaghoubi (2016) e Memon et al. (2018) operam suas pesquisas na identificação dos fatores que expliquem o nível de alavancagem e a utilização de dívidas de diferentes vencimentos nas empresas, apontando que estes aspectos ainda permanecem atuais como interesse de pesquisadores em finanças.

Especificamente acerca do nível de endividamento, a principal corrente teórica existente e disseminada há algumas décadas é de que a dívida gera alguns benefícios, como a vantagem fiscal, mas também traz custos associados à alavancagem excessivamente alta, como é o caso dos custos de falência (Dangl \& Zechner, 2016). Diante disto, conforme levantamento realizado por Yaghoubi (2017), diversos pesquisadores tem argumentado que as empresas possuem um nível de estrutura de capital ótima e tentam permanecer nesta zona ideal, ajustando-se ao alvo quando necessário (Yaghoubi, 2017). Isto faz com que o nível de endividamento seja fundamental para as organizações, em que a estrutura de capital maximizadora de valor de cada empresa varia de acordo com o ambiente interno e externo corporativo (Mouton \& Smith, 
2016).

Quanto à maturidade da dívida, Arslan e Karan (2006) destacam que ao longo do tempo, as pesquisas acerca da estrutura de capital corporativa passaram da escolha entre dívida e capital próprio para foco na compreensão das características da dívida, sobretudo quanto ao seu vencimento. Usualmente, utilizando os princípios contábeis, a dívida é mensurada como de curto prazo e de longo prazo, sendo doze meses o fator divisor (Yaghoubi, 2017). Quanto as suas consequências, Arslan e Karan (2006) defendem que a dívida de curto prazo tem três principais riscos, sobretudo em mercados emergentes, sendo o risco dos juros, do refinanciamento e da liquidez corporativa (Arslan \& Karan, 2006), o que torna seu correto dimensionado imprescindível para a sobrevivência das organizações.

Com base neste ínterim, discute-se na sequência a volatilidade do fluxo de caixa e a volatilidade da disponibilidade de caixa como fatores explicativos do nível da dívida e da maturidade da dívida, formulando, concomitantemente, as hipóteses de pesquisa que serão testadas em empresas industriais brasileiras.

\subsection{Volatilidade do Fluxo de Caixa}

Medidas de volatilidade, via de regra, são operacionalizadas pelo desvio-padrão da variável em estudo, a efeito do observado em Veirman e Levin (2018). A volatilidade do fluxo de caixa, especificamente, é uma medida de risco do negócio que mede a probabilidade de uma empresa enfrentar dificuldades financeiras, sendo geralmente definida como o desvio-padrão do fluxo de caixa operacional em um determinado período de tempo (Memon et al., 2018). De acordo com literatura prévia, a volatilidade do fluxo de caixa tem se apresentado como importante determinante do nível e da maturidade da dívida, sendo que, conforme Memon et al. (2018), são várias as explicações teóricas que levam a acreditar que a volatilidade afeta a estrutura de alavancagem das corporações.

Partindo de modelos da década de 1970, Keefe e Yaghoubi (2016) defendem que existe relação positiva entre a volatilidade do fluxo de caixa e o custo da dívida. Este fato faz com que a maior volatilidade do fluxo de caixa proporcione aumento no valor do patrimônio líquido e diminuição do endividamento via terceiros, visto que o custo marginal da dívida é acrescido (Keefe \& Yaghoubi, 2016), fazendo com que os benefícios do endividamento cessem em patamares inferiores. Logo, tem-se que organizações com alta volatilidade do fluxo de caixa operam com níveis de endividamento inferior, com vistas a reduzir sua exposição ao custo maior da dívida e consequente risco de falência.

De fato, Memon et al. (2018) argumentam que a alta variabilidade do fluxo de caixa e o maior custo vinculado a dificuldades financeiras são características nítidas de empresas com maior grau de risco de insolvência. Este aspecto pode ser explicado pela teoria trade-off em que empresas de alto risco optam por dívida relativamente menor. Em outras palavras, tem-se que à medida que a volatilidade aumenta, ela maximiza as chances de organizações entrarem em dificuldades financeiras e, como resultado, diminui o valor atual das vantagens fiscais da dívida. Evidências empíricas têm majoritariamente apontado que a influência da volatilidade do fluxo de caixa no nível da dívida é negativa, como observado no recente estudo de Martins e Vasconcelos (2020). Logo, elabora-se a seguinte hipótese de pesquisa:

$H_{1}$ - A volatilidade do fluxo de caixa tem efeito negativo no nível da dívida de empresas industriais brasileiras.

A volatilidade do fluxo de caixa é representada principalmente por medidas que captam o desviopadrão do fluxo de caixa operacional gerado em um período de tempo (Yaghoubi, 2017), sendo que a referida variabilidade existente pode ser resultante da queda ou do acréscimo do fluxo de caixa gerado. Este fator de tendência é importante, visto que conforme Ferreira e Vilela (2004), as disponibilidades de caixa e os fluxos de caixa auferidos (como geradores das disponibilidades), quando apropriados, atuam como propulsores de benefícios às corporações, tendo-se, dentre eles, a redução da probabilidade de dificuldades financeiras e a minimização dos custos de captação de recursos externos (Ferreira \& Vilela, 2004). Logo, é de ser esperar que a volatilidade do fluxo de caixa, quando apresenta tendência positiva, não é tão sensível ao nível inferior de endividamento corporativo comparativamente a volatilidade com tendência negativa, sugerindo a seguinte hipótese de pesquisa:

$\mathrm{H}_{2}$ - A tendência crescente do fluxo de caixa atenua o efeito negativo da volatilidade do fluxo de caixa no nível da dívida de empresas industriais brasileiras.

Quanto à influência da volatilidade do fluxo de caixa na maturidade da dívida, Keefe e Yaghoubi (2016) sugerem, baseando-se em pesquisa anterior, que o custo do endividamento tende a crescer conforme aumento no prazo de vencimento da dívida. Esta prerrogativa pode ser considerada natural, visto que quanto maior o prazo para pagamento de uma dívida, maior tende a ser o risco atrelado, proporcionando aumento na taxa de juros. Empresas com alta volatilidade do fluxo de caixa, por já estarem, mediante esta característica, expostas a taxas de juros maiores, tenderão a fazer uso mais extensivo de fontes de financiamento de curto prazo, visando melhor contrabalancear os custos e benefícios da dívida. 
Em perspectiva empírica, diversos são os estudos que buscam entender as questões vinculadas à maturidade da dívida, seus determinantes e consequências para as empresas. A efeito, Miltersen e Toroso (2008) defendem que o trade-off existente para se alcançar o vencimento ótimo da dívida deve considerar os benefícios da flexibilidade do vencimento e os custos de emissão da dívida de longo prazo. Os resultados comprovam a importância do contrabalanceamento dos dois fatores (flexibilidade e custos) e, ainda, apontam que quanto maior a volatilidade dos processos que geram resultados nas empresas (e que também participam da geração de fluxo de caixa), menor é a maturidade da dívida. Com base nos preceitos teóricos e empíricos abordados, tem-se a seguinte hipótese de pesquisa:

$H_{3}$ - A volatilidade do fluxo de caixa tem efeito negativo na maturidade da dívida de empresas industriais brasileiras.

Sabe-se que o aumento do risco na geração de fluxo de caixa reduz o prazo médio de vencimento ótimo da dívida (Miltersen \& Toroso, 2008). Adicionalmente, tem-se que a taxa de crescimento (positiva) do fluxo de caixa tem efeito oposto (Dangl \& Zechner, 2016), ou seja, se o fluxo de caixa apresentar tendência positiva, mesmo que volátil, o vencimento da dívida ótimo tende a ser maximizado. De acordo com Dangl e Zechner (2016), este fenômeno ocorre porque o compromisso de diminuir o endividamento em resposta a fluxos de caixa decrescentes é menos valioso para empresas que apresentam taxas de crescimento do fluxo de caixa esperado. Assim, se tem subsídios para a elaboração da hipótese de pesquisa que segue:

$H_{4}$ - A tendência crescente do fluxo de caixa atenua o efeito negativo da volatilidade do fluxo de caixa na maturidade da dívida de empresas industriais brasileiras.

\subsection{Volatilidade da Disponibilidade de Caixa}

A geração de recursos por intermédio dos fluxos de caixa pode ser vista como um substituto do dinheiro mantido como folga financeira, sendo que empresas com fluxos de caixa mais voláteis enfrentam maior probabilidade de sofrer escassez de disponível (caixa e equivalentes de caixa) devido à deterioração inesperada destes fluxos advindos das operações corporativas (Ferreira \& Vilela, 2004). De fato, Dang, Kim e Shin (2012) mencionam que empresas com alta volatilidade nos lucros e, assim, provavelmente também nos fluxos de caixa, tendem a ter acesso limitado ao mercado financeiro para fazer ajustes na estrutura de capital (Dang et al., 2012), sobretudo para a contração de empréstimos, visto seus rendimentos oscilantes a fim de cumprir as obrigações da dívida. Conforme argumentos expostos, é esperado que fluxos de caixa instáveis afetem negativamente a disponibilidade de caixa, que sofrerá neste período alta volatilidade vinculada ao declínio dos recursos disponíveis. Logo, as perspectivas discutidas levam a elaboração da seguinte hipótese:

$H_{5}-$ A volatilidade da disponibilidade de caixa tem efeito negativo no nível da dívida de empresas industriais brasileiras.

Em discussão acerca de teorias de estrutura de capital, que estão principalmente ligadas à busca da melhor forma de se captar recursos para as corporações, Bhardwaj (2018) menciona que quando gestores de uma organização acumulam volume relevante de folga financeira, há uma tendência maior de se tornarem imunes à disciplina de mercado (Bhardwaj, 2018). Esta folga financeira, que está vinculada a disponibilidades elevadas de caixa, pode fornecer a determinada empresa potencial de investimentos ou, ainda, caso a organização opte por permanecer com excesso de caixa, proporciona possibilidade facilitada de buscar recursos de terceiros, visto que os credores consideram as disponibilidades como potenciais aos pagamentos da dívida parcelada.

Logo, por mais que a volatilidade da disponibilidade de caixa tenda a dificultar o acesso ao capital de terceiros (Dang et al., 2012), quando esta é derivada de recursos financeiros em excesso e crescentes na organização, o acesso a empréstimos e financiamos tende a ser facilitado. Com base nisto, se apresenta a seguinte hipótese de pesquisa:

$H_{6}$ - A tendência crescente da disponibilidade de caixa atenua o efeito negativo da volatilidade da disponibilidade de caixa no nível da dívida de empresas industriais brasileiras.

Bates, Kahle e Stulz (2009) averiguaram que as disponibilidades de caixa das empresas industriais norte-americanas têm, ao longo do tempo, aumentado, com vistas a atender a precauções no atual mercado altamente competitivo e globalizado. Este fato deve-se, principalmente, porque os fluxos de caixa das empresas têm se tornado mais arriscados (voláteis) (Bates et al., 2009), sugerindo relação entre a geração de caixa (fluxos) e sua manutenção em dinheiro (disponibilidades).

Dito isto e, ainda, sabendo que as evidências empíricas de Keefe e Yaghoubi (2016) apontam que um aumento no desvio-padrão da volatilidade dos fluxos de caixa, que se transformara posteriormente em 
caixa, implica em uma redução de aproximadamente $24 \%$ no índice de dívida de longo prazo (maturidade) para organizações norte-americanas; e, ainda, de Memon et al. (2018) que verificaram, no cenário chinês, que a volatilidade dos aspectos ligados ao caixa, além de resultar em níveis de alavancagem mais baixos as empresas, proporciona a redução de $26,62 \%$ na probabilidade de emissão de debêntures e outras dívidas de longo prazo, elabora-se a seguinte hipótese de pesquisa:

$H_{7}$ - A volatilidade da disponibilidade de caixa tem efeito negativo na maturidade da dívida de empresas industriais brasileiras.

Com base no discutido até o momento, permite-se afirmar que o aumento da volatilidade eleva a probabilidade de ocorrência situacional em que uma empresa passa a não ser mais capaz de aproveitar as vantagens fiscais sobre a dívida (Memon et al., 2018), reduzindo o seu nível ótimo de capital de terceiros e, por consequência, fazendo com que tais organizações mais arriscadas (maior volatilidade) fomentem em menor proporção a utilização de recursos de terceiros (Memon et al., 2018) e de dívidas de longo prazo. Todavia, sabendo que a referida volatilidade pode se dar por disponibilidades crescentes ou decrescentes ao longo do tempo e, ainda, que conforme Bhardwaj (2018) as premissas consolidadas de mercado podem ser mitigadas quando o movimento do caixa é para a abundância de recursos (movimento crescente), temse a composição da seguinte hipótese de pesquisa:

$H_{8}$ - A tendência crescente da disponibilidade de caixa atenua o efeito negativo da volatilidade da disponibilidade de caixa na maturidade da dívida de empresas industriais brasileiras.

\section{Procedimentos Metodológicos}

Este estudo, que tem por objetivo verificar o efeito da volatilidade do fluxo de caixa e da volatilidade da disponibilidade de caixa na estrutura de capital de empresas industriais brasileiras é classificado como descritivo, visto que observa variáveis sem manipula-las. Além disso, a pesquisa configura-se como documental, uma vez que as informações utilizadas para cálculo das variáveis foram obtidas por intermédio

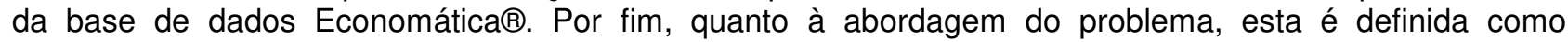
quantitativa, pois se verifica a influência das variáveis mediante a operacionalização de técnicas estatísticas.

A população da pesquisa abrangeu todas as empresas industriais brasileiras listadas na Brasil, Bolsa, Balcão - B3. Já a amostra foi composta por organizações que possuíam dados para operacionalização das variáveis em todos os períodos estudados, abrangendo a lacuna temporal de 5 anos - 2014 a 2018 - (informações de 2010 a 2013 também foram utilizadas, todavia, apenas para cálculo das variáveis volatilidade do fluxo de caixa e volatilidade da disponibilidade de caixa). Cabe destacar que 2010 coincide com o ano de adoção das normas internacionais de contabilidade no Brasil, fazendo com que as informações contábeis utilizadas nesta pesquisa sejam consistentes durante todo o período de análise.

Ademais, foram excluídas as empresas cujas variáveis foram consideradas outliers por estarem mais de três desvios-padrões distante da média, o que poderia tendenciar os achados. Além disso, adicionalmente, foi aplicada a winsorização dos dados a 1\% em ambas as caudas da distribuição, ou seja, definiu-se os extremos como $1 \%$ e $99 \%$ a fim de substituir os possíveis outliers que poderiam permanecer. Com estes preceitos, a amostra de pesquisa ficou composta por 77 empresas, totalizando 385 observações.

Em referência a análise dos dados, operados em base anualizada, inicialmente foi elaborada a estatística descritiva das variáveis em estudo, sendo estas as dependentes de estrutura de capital - nível e maturidade da dívida -, as independentes de volatilidade - do fluxo e da disponibilidade de caixa - e as demais variáveis de controle - rentabilidade, tamanho, liquidez, crescimento das vendas, efeito fixo de setor e efeito fixo de ano. Com base nestas, foram operacionalizados, portanto, os modelos de regressões múltiplas. Para melhor compreensão, a seguir apresenta-se o Quadro 1, que contém as variáveis relacionadas ao estudo, além de sua descrição, equação e autores que embasam a forma como estas são dimensionados visando a sua aplicação empírica.

Por intermédio das variáveis apresentadas no Quadro 1, foram elaborados os modelos de regressão, sendo ao todo oito modelos, constituídos da seguinte forma: (1) e (2) com as variáveis dependentes de nível da dívida e com as independentes de volatilidade do fluxo de caixa (hipóteses $H_{1}$ e $\mathrm{H}_{2}$ ); (3) e (4) com as variáveis dependentes de maturidade da dívida e com as independentes de volatilidade do fluxo de caixa (hipóteses $\mathrm{H}_{3}$ e $H_{4}$ ); (5) e (6) com as variáveis dependentes de nível da dívida e com as independentes de volatilidade da disponibilidade de caixa (hipóteses $H_{5}$ e $H_{6}$ ); e, (7) e (8) com as variáveis dependentes de maturidade da dívida e com as independentes de volatilidade da disponibilidade de caixa (hipóteses $\mathrm{H}_{7}$ e $\mathrm{H}_{8}$ ). 


\begin{tabular}{|c|c|c|c|}
\hline Variável & Descrição & Equação & Autores \\
\hline \multicolumn{4}{|c|}{ Variáveis Dependentes - Nível da Dívida } \\
\hline $\begin{array}{l}\text { Endividamento Total } \\
\text { (EndT) }\end{array}$ & $\begin{array}{l}\text { Relação das Dívidas Totais } \\
\text { com o Total dos Ativos }\end{array}$ & $\begin{array}{c}\text { Passivo Circulante }+ \text { Passivo } \\
\text { Não Circulante } \\
\text { Ativo Total }\end{array}$ & $\begin{array}{c}\text { Keefe e Yaghoubi } \\
(2016) ; \text { Memon et al. } \\
(2018)\end{array}$ \\
\hline $\begin{array}{l}\text { Endividamento Oneroso } \\
\text { (EndO) }\end{array}$ & $\begin{array}{c}\text { Relação das Dívidas Onerosas } \\
\text { com o Total dos Ativos }\end{array}$ & $\begin{array}{c}\text { Empréstimos e Financiamentos } \\
\text { de Curto Prazo e de Longo } \\
\text { Prazo + Debêntures } \\
\text { Ativo Total }\end{array}$ & $\begin{array}{l}\text { Keefe e Yaghoubi } \\
\text { (2016) }\end{array}$ \\
\hline \multicolumn{4}{|c|}{ Variáveis Dependentes - Maturidade da Dívida } \\
\hline $\begin{array}{l}\text { Endividamento de Longo } \\
\text { Prazo (ELP) }\end{array}$ & $\begin{array}{l}\text { Relação das Dívidas de Longo } \\
\text { Prazo com as Dívidas Totais }\end{array}$ & $\begin{array}{c}\text { Passivo Não Circulante } \\
\text { Passivo Circulante }+ \text { Passivo } \\
\text { Não Circulante } \\
\end{array}$ & Cai et al. (2008) \\
\hline $\begin{array}{l}\text { Endividamento Oneroso } \\
\text { de Longo Prazo (EOLP) }\end{array}$ & $\begin{array}{c}\text { Relação das Dívidas Onerosas } \\
\text { de Longo Prazo com as Dívidas } \\
\text { Onerosas }\end{array}$ & $\begin{array}{c}\text { Empréstimos e Financiamentos } \\
\text { de Longo Prazo + Debêntures } \\
\text { de Longo Prazo } \\
\text { Empréstimos e Financiamentos } \\
\text { de Curto Prazo e de Longo } \\
\text { Prazo + Debêntures de Curto } \\
\text { Prazo e de Longo Prazo }\end{array}$ & Proposta pelos Autores \\
\hline \multicolumn{4}{|c|}{ Variáveis Independentes } \\
\hline $\begin{array}{l}\text { Volatilidade do Fluxo } \\
\text { de Caixa } \\
\text { (VFC) }\end{array}$ & $\begin{array}{c}\text { Desvio-padrão da relação entre } \\
\text { o Fluxo de Caixa Operacional e } \\
\text { o Ativo Líquido dos últimos } 5 \\
\text { exercícios }\end{array}$ & $\begin{array}{c}\text { Desvio padrão dos últimos } 5 \text { exercícios da } \\
\text { seguinte relação: } \\
\frac{\text { Fluxo de Caixa Operacional }}{\text { Ativo Líquido }}\end{array}$ & Memon et al. (2018) \\
\hline $\begin{array}{l}\text { Dummy de Tendência da } \\
\text { Volatilidade do Fluxo de } \\
\text { Caixa (D_VFC) }\end{array}$ & $\begin{array}{l}\text { Variável dummy, que recebe } \\
\text { valor } 1 \text { se a tendência } \\
\text { (inclinação) do Fluxo de Caixa } \\
\text { Operacional e o Ativo Líquido } \\
\text { dos últimos } 5 \text { exercícios for } \\
\text { crescente; e, 0, caso contrário }\end{array}$ & $\begin{array}{l}\text { Tendência (inclinação) dos últimos } 5 \\
\text { exercícios da seguinte relação: } \\
\frac{\text { Fluxo de Caixa Operacional }}{\text { Ativo Líquido }}\end{array}$ & Proposta pelos Autores \\
\hline $\begin{array}{l}\text { Volatilidade da } \\
\text { Disponibilidade de Caixa } \\
\text { (VDC) }\end{array}$ & $\begin{array}{l}\text { Desvio-padrão da relação entre } \\
\text { o Caixa e seus Equivalentes e } \\
\text { o Ativo Líquido dos últimos } 5 \\
\text { exercícios }\end{array}$ & $\begin{array}{l}\text { Desvio padrão dos últimos } 5 \text { exercícios da } \\
\text { seguinte relação: } \\
\frac{\text { Caixa e Equivalentes de Caixa }}{\text { Ativo Líquido }}\end{array}$ & Proposta pelos Autores \\
\hline $\begin{array}{c}\text { Dummy de Tendência da } \\
\text { Volatilidade da } \\
\text { Disponibilidade de Caixa } \\
\text { (D_VDC) }\end{array}$ & $\begin{array}{l}\text { Variável dummy, que recebe } \\
\text { valor } 1 \text { se a tendência } \\
\text { (inclinação) entre o Caixa e } \\
\text { seus Equivalentes e o Ativo } \\
\text { Líquido dos últimos } 5 \\
\text { exercícios for crescente; } 0 \text {, } \\
\text { caso contrário } \\
\end{array}$ & $\begin{array}{l}\text { Tendência (inclinação) dos últimos } 5 \\
\text { exercícios da seguinte relação: } \\
\frac{\text { Caixa e Equivalentes de Caixa }}{\text { Ativo Líquido }}\end{array}$ & Proposta pelos Autores \\
\hline \multicolumn{4}{|c|}{ Variáveis de Controle - Específicas das Firmas } \\
\hline Rentabilidade (RENT) & $\begin{array}{c}\text { Relação entre EBIT e o Ativo } \\
\text { Total }\end{array}$ & $\begin{array}{c}\text { Earnings Before Interest and } \\
\text { Taxes (EBIT) } \\
\text { Ativo Total }\end{array}$ & $\begin{array}{l}\text { Mouton e Smith (2016); } \\
\text { Memon et al. (2018) }\end{array}$ \\
\hline Tamanho (TAM) & Logaritmo natural do Ativo Total & LN do Ativo Total & $\begin{array}{c}\text { Keefe e Yaghoubi } \\
\text { (2016); Tripathy e Asija } \\
\text { (2017) }\end{array}$ \\
\hline Liquidez (LIQ) & $\begin{array}{l}\text { Relação entre Ativo Circulante } \\
\text { e Passivo Circulante. }\end{array}$ & $\frac{\text { Ativo Circulante }}{\text { Passivo Circulante }}$ & $\begin{array}{c}\text { Cai et al. (2008); } \\
\text { Tripathy e Asija (2017) }\end{array}$ \\
\hline $\begin{array}{l}\text { Crescimento das Vendas } \\
\text { (CV) }\end{array}$ & $\begin{array}{c}\text { Relação entre a variação das } \\
\text { Vendas do período anterior } \\
\text { para o atual. }\end{array}$ & $\frac{\text { Vendas } t-\text { Vendas } t-1}{\text { Vendas } t-1}$ & Mouton e Smith (2016) \\
\hline \multicolumn{4}{|c|}{ Variáveis de Controle - Efeitos Fixos } \\
\hline Efeito Fixo de Setor & $\begin{array}{l}\text { Classificação setor econômico } \\
\text { Bovespa tendo-se: 1) Bens } \\
\text { industriais; 2) Consumo cíclico; } \\
\text { 3) Consumo não cíclico; 4) } \\
\text { Materiais básicos; e, 5) Outros } \\
\text { setores industriais. }\end{array}$ & Não se aplica & $\begin{array}{c}\text { Adaptado de Keefe e } \\
\text { Yaghoubi (2016); } \\
\text { Veirman e Levin (2018) }\end{array}$ \\
\hline Efeito Fixo de Ano & $\begin{array}{c}\text { Período de estudo, tendo-se: 1) } \\
\text { 2014; 2) 2015; 3) 2016; 4) } \\
\text { 2017; e, 5) 2018 }\end{array}$ & Não se aplica & $\begin{array}{l}\text { Keefe e Yaghoubi } \\
\text { (2016); Veirman e } \\
\text { Levin (2018) } \\
\end{array}$ \\
\hline
\end{tabular}

\section{Quadro 1: Variáveis Dependentes, Independentes e de Controle}

Observações: 1) Ativo líquido = total dos ativos (-) caixa e equivalentes de caixa; 2) as variáveis dummy de inclinação (tendência) são derivadas da "inclinação da reta da regressão linear para os pontos de dados estimados"; 3) as variáveis designadas como "propostas pelos autores", referem-se, exclusivamente, para a configuração metodológica adotada nesta pesquisa. Seu uso em outras configurações é de conhecimento da literatura prévia, sobretudo na área de finanças; e, 4) De acordo com Veirman e Levin (2018), ao controlar, por efeitos fixos, uma gama de fatores, se produz estimativas mais confiáveis da volatilidade. Portanto, "Efeito Fixo de Setor" e "Efeito Fixo de Ano" são operacionalizados, nesta pesquisa, para produzir modelos mais robustos.

Fonte: Dados da pesquisa. 
Cabe destacar, ainda, que todos os modelos apresentam ainda as variáveis de controle. Para melhor compreensão, segue abaixo as equações.

$$
\begin{aligned}
& \text { EndT }=\beta_{0}+\beta_{1} \text { VFC }+\beta_{2} \text { D_VFC }+\beta_{3} \text { RENT }+\beta_{4} T A M+\beta_{5} L I Q+\beta_{6} C V+\Sigma \text { EfeitoFixoSetorSEfeitoFixoAno }+\varepsilon \\
& \text { EndO }=\beta_{0}+\beta_{1} \text { VFC }+\beta_{2} \text { D_VFC }+\beta_{3} \text { RENT }+\beta_{4} \text { TAM }+\beta_{5} \text { LIQ }+\beta_{6} C V+\Sigma \text { EfeitoFixoSetor }+\Sigma \text { EfeitoFixoAno }+\varepsilon \\
& E L P=\beta_{0}+\beta_{1} \text { VFC }+\beta_{2} \text { D_VFC }+\beta_{3} R E N T+\beta_{4} T A M+\beta_{5} L I Q+\beta_{6} C V+\text { EEfeitoFixoSetor }+ \text { EEfeitoFixoAno }+\varepsilon \\
& E O L P=\beta_{0}+\beta_{1} V F C+\beta_{2} D \_V F C+\beta_{3} \text { RENT }+\beta_{4} T A M+\beta_{5} L I Q+\beta_{6} C V+\Sigma E \text { feitoFixoSetor }+\Sigma \text { EfeitoFixoAno }+\varepsilon \\
& \text { EndT }=\beta_{0}+\beta_{1} V D C+\beta_{2} D \_V D C+\beta_{3} R E N T+\beta_{4} T A M+\beta_{5} L I Q+\beta_{6} C V+\text { EEfeitoFixoSetor }+\Sigma \text { Ef eitoFixoAno }+\varepsilon \\
& \text { EndO }=\beta_{0}+\beta_{1} \text { VDC }+\beta_{2} \text { D_VDC }+\beta_{3} \text { RENT }+\beta_{4} \text { TAM }+\beta_{5} \text { LIQ }+\beta_{6} C V+\text { EEfeitoFixoSetor }+ \text { EEfeitoFixoAno }+\varepsilon \\
& E L P=\beta_{0}+\beta_{1} V D C+\beta_{2} D \_V D C+\beta_{3} R E N T+\beta_{4} T A M+\beta_{5} L I Q+\beta_{6} C V+\Sigma E \text { feitoFixoSetor }+ \text { EEfeitoFixoAno }+\varepsilon \\
& E O L P=\beta_{0}+\beta_{1} V D C+\beta_{2} D \_V D C+\beta_{3} R E N T+\beta_{4} T A M+\beta_{5} L I Q+\beta_{6} C V+\Sigma E \text { feitoFixoSetor }+\Sigma E \text { feitoFixoAno }+\varepsilon
\end{aligned}
$$

Observados os modelos da pesquisa, destaca-se, por fim, que para tabulação das variáveis fez-se uso de planilha eletrônica. Posteriormente, a fim de verificar o efeito da volatilidade do fluxo de caixa e da volatilidade da disponibilidade de caixa na estrutura de capital de empresas industriais brasileiras, vinculado, portanto, ao objetivo de pesquisa, fez-se uso do método estatístico de regressão linear múltipla com auxílio do software especializado IBM STATA (Data Analysis and Statistical Software) versão 12. Por fim, é essencial destacar que os pressupostos para operacionalização dos modelos de regressão foram realizados - normalidade, multicolinearidade, autocorrelação e heterocedasticidade - também no IBM STATA versão 12, sendo estes apresentados, de forma mais abrangente, na seção seguinte de análise dos dados.

\section{Análise dos Dados}

\begin{tabular}{|c|c|c|c|c|}
\hline \multirow{2}{*}{ Variáveis } & \multicolumn{4}{|c|}{ Variáveis Numéricas } \\
\hline & Média & Desvio-Padrão & Mínimo & Máximo \\
\hline EndT & 0,6675 & 0,2792 & 0,1320 & 1,7400 \\
\hline EndO & 0,3467 & 0,1778 & 0,0341 & 0,8431 \\
\hline ELP & 0,4764 & 0,2015 & 0,0463 & 0,8555 \\
\hline EOLP & 0,5612 & 0,2635 & 0,0000 & 0,9707 \\
\hline VFC & 0,0416 & 0,0282 & 0,0064 & 0,1528 \\
\hline VDC & 0,0372 & 0,0345 & 0,0006 & 0,1846 \\
\hline RENT & 0,0499 & 0,0825 & $-0,4054$ & 0,2908 \\
\hline TAM & 15,0355 & 1,9749 & 11,1514 & 20,6181 \\
\hline LIQ & 1,6750 & 1,0882 & 0,0718 & 9,0528 \\
\hline $\mathrm{CV}$ & 0,0407 & 0,1671 & $-0,4839$ & 0,5995 \\
\hline \multirow{2}{*}{ Variáveis } & \multicolumn{4}{|c|}{ Variáveis Categóricas } \\
\hline & \multicolumn{2}{|c|}{ Tendência (inclinação) Decrescente } & \multicolumn{2}{|c|}{ Tendência (inclinação) Crescente } \\
\hline $\begin{array}{l}\text { D_VFC } \\
\text { D_VDC }\end{array}$ & \multicolumn{2}{|c|}{$229(59,5 \%)$} & \multicolumn{2}{|c|}{$156(40,5 \%)$} \\
\hline Total & \multicolumn{4}{|c|}{385 observações $(100,00 \%)$} \\
\hline \multicolumn{5}{|c|}{$\begin{array}{l}\text { Legenda: EndT = Endividamento Total; EndO = Endividamento Oneroso; ELP = Endividamento de Longo Prazo; EOLP } \\
=\text { Endividamento Oneroso de Longo Prazo; VFC = Volatilidade do Fluxo de Caixa; VDC = Volatilidade da } \\
\text { Disponibilidade de Caixa; RENT = Rentabilidade; TAM = Tamanho; LIQ = Liquidez; CV =Crescimento das Vendas; } \\
\text { D_VFC = Dummy de tendência (inclinação) da Volatilidade do Fluxo de Caixa; D_VDC = Dummy de tendência } \\
\text { (inclinação) da Volatilidade da Disponibilidade de Caixa. } \\
\text { Fonte: Dados da pesquisa. }\end{array}$} \\
\hline
\end{tabular}

\subsection{Estatística Descritiva}

Antes de adentrar aos modelos de regressão que visam atender propriamente ao objetivo de pesquisa, é essencial compreender as características gerais da amostra. Para tanto, apresenta-se a Tabela 1, que contém média, desvio-padrão, mínimo e máximo das variáveis numéricas em estudo, bem como referência proporcional das variáveis do tipo categóricas.

Tabela 1

Estatística Descritiva das Variáveis Numéricas e Categóricas

Mediante dados apresentados na Tabela 1, percebe-se que, em média, aproximadamente dois terços do capital utilizado pelas organizações industriais brasileiras advêm de terceiros. Este número está 
potencializado, visto que, algumas empresas, por apresentarem patrimônio líquido negativo (passivo a descoberto), apresentam relação de endividamento total superior a 1. Ainda assim, é possível inferir que a proporção de uso de capital de terceiros por empresas brasileiras é elevada, o que maximiza a importância de se compreender os determinantes da estrutura da dívida. Além disso, o endividamento oneroso corresponde a pouco mais da metade do endividamento total, apontando que empréstimos e financiamentos e debêntures constituem fontes usufruídas de maneira intensa pelas organizações na busca por recursos de terceiros.

Compreendido às facetas gerais acerca do nível de endividamento, observa-se, na sequência, quanto à maturidade deste, que $47,6 \%$ das dívidas corporativas estão no longo prazo, ou seja, apresentam prazo de vencimento superior a um ano, subindo para $56,1 \%$ quando considerado exclusivamente 0 endividamento oneroso. E natural que haja um crescimento percentual relevante nas dívidas onerosas de longo prazo em comparação com as dívidas gerais de igual tempo, visto que, habitualmente, as dívidas onerosas subsidiam compras de ativos fixos que irão gerar resultados em extensivos períodos, sendo condicionadas, portanto, também há tempos superiores de pagamentos, enquanto em dívidas gerais se tem embutido itens como fornecedores, salários, tributos, etc. que são, por natureza, majoritariamente de curto prazo.

\subsection{Modelos de regressão}

Mediante as regressões que seguem, observa-se 0 efeito das variáveis independentes de volatilidade - do fluxo de caixa e da disponibilidade de caixa -, de suas tendências (inclinação) e, ainda, das variáveis de controle - rentabilidade, tamanho, liquidez e crescimento das vendas - nas variáveis dependentes de estrutura de capital, que estabelecem o nível e a maturidade da dívida. Tais relações estão vinculadas, em etapas, às hipóteses 1 a 8, tendo seu início apresentado na Tabela 2, que segue para posterior descrição.

Tabela 2

Efeito da Volatilidade do Fluxo de Caixa na Estrutura de Capital - Nível da Dívida

\begin{tabular}{|c|c|c|c|c|c|c|}
\hline \multirow[t]{2}{*}{ Variáveis } & \multicolumn{3}{|c|}{$\begin{array}{l}\text { Endividamento Total } \\
\text { (EndT) }\end{array}$} & \multicolumn{3}{|c|}{$\begin{array}{l}\text { Endividamento Oneroso } \\
\text { (EndO) }\end{array}$} \\
\hline & Coef. & t test & Sig. & Coef. & t test & Sig. \\
\hline VFC & 2,9179 & 5,91 & $0,000^{*}$ & 0,5450 & 1,45 & 0,147 \\
\hline D_VFC & 0,0149 & 0,72 & 0,471 & 0,0327 & 1,76 & $0,080^{* * *}$ \\
\hline$\overline{\text { RENT }}$ & $-0,7428$ & $-3,81$ & $0,000^{*}$ & $-0,4427$ & $-2,94$ & $0,003^{\star}$ \\
\hline TAM & $-0,0011$ & $-0,17$ & 0,862 & 0,0185 & 3,81 & $0,000^{*}$ \\
\hline LIQ & $-0,1037$ & $-7,12$ & $0,000^{*}$ & $-0,3004$ & $-4,20$ & $0,000^{*}$ \\
\hline CV & 0,0225 & 0,29 & 0,770 & 0,1391 & 2,66 & $0,008^{*}$ \\
\hline CONS & 0,7741 & 6,85 & $0,000^{*}$ & 0,1135 & 1,39 & 0,167 \\
\hline $\mathrm{R}^{2}$ & & 0,4814 & & & 949 & \\
\hline Sig. Modelo & & 0,0000 & & & 000 & \\
\hline Nr. Obs. & & 385 & & & 35 & \\
\hline EF de Setor & & Sim & & & $\mathrm{m}$ & \\
\hline EF de Ano & & Sim & & & $m$ & \\
\hline Jarque-Bera & & 0,0001 & & & 099 & \\
\hline VIF & & $\leq 1,70$ & & & 70 & \\
\hline Durbin-Watson & & 2,0987 & & & 500 & \\
\hline White Test & & 0,0000 & & & 02 & \\
\hline Matriz White (RR) & & Sim & & & $\mathrm{m}$ & \\
\hline
\end{tabular}

Legenda: VFC = Volatilidade do Fluxo de Caixa; D_VFC = Dummy de tendência (inclinação) da Volatilidade do Fluxo de Caixa; RENT = Rentabilidade; $\mathrm{TAM}=$ Tamanho; $\mathrm{LIQ}=$ Liquidez; CV = Crescimento das Vendas; $\mathrm{EF}$ = Efeito Fixo; VIF = Variance Inflation Factor, RR = Regressão Robusta.

Nota: Significância ao nível de ${ }^{*} 1 \% ;{ }^{* *} 5 \% ;{ }^{* * *} 10 \%$.

Fonte: Dados da pesquisa.

Na Tabela 2, apresenta-se a relação da volatilidade do fluxo de caixa e de sua tendência no nível da dívida (hipóteses 1 e 2), sendo os modelos estatísticos em questão significativos ao nível de 1\%, o que permite inferências. As variáveis independentes e de controle, mediante $\mathrm{R}^{2}$, apresentaram poder explicado de $48,14 \%$ no endividamento total e $19,49 \%$ para com o endividamento oneroso. O número de observações nestes e em todos os modelos que seguem é de 385, derivadas das 77 empresas industriais brasileiras estudadas ao longo de 5 anos. Ressalta-se, ainda, que todos os modelos apresentam controle de efeito fixo de ano e de setor, visando considerar possíveis mudanças no comportamento das variáveis conforme as características citadas.

Em referência aos pressupostos dos modelos, a normalidade (teste de Jarque-Bera) foi violada quando da variável dependente endividamento total. Neste caso em específico, os dados foram relaxados mediante teorema central do limite, que conforme Couto, Oliveira, Torres e Morais (2015), sua aplicação 
dar-se-á quando o tamanho da amostra for de pelo menos 30 casos, condizente, portanto, com a condição deste estudo. Além disso, Freund \& Simon (2000) asseveram que os pressupostos do teorema central do limite são amplamente aceitos na literatura estatística, garantindo o procedimento adotado. Ademais, o VIF (variance inflation factor) das variáveis foi igual ou inferior a 1,70, distante no limite máximo aceitável que é de 5 , não havendo, portanto, problemas de multicolinearidade nos modelos.

O teste de autocorrelação dos resíduos (Durbin-Watson) ficou, em ambos os modelos, entre o aceitável de 1 e 3 e, ainda, bastante próximos de 2, que é o ideal, atendendo, portanto, as especificidades das regressões. Por fim, em ambos os modelos foi detectado, mediante teste de White, problemas de heterocedasticidade. Para superar esta condição, realizou-se regressão robusta, que conforme Fávero, Belfiore, Silva e Chan (2009), insere a matriz White, ajustando os erros padrão mediante heterocedasticidade do modelo.

Quanto aos resultados, tem-se que a volatilidade do fluxo de caixa (VFC) apresenta relação positiva com o nível de dívida das empresas, todavia, os achados são significativos apenas para a variável independente de endividamento total. Tais resultados apontam, portanto, que empresas com maior variabilidade do fluxo de caixa gerado ao longo do tempo utilizam de forma mais intensa recursos advindos de terceiros (endividamento). A tendência (inclinação), dimensionada pela variável D_VFC, por sua vez, aponta que fluxos de caixa crescentes facilitam o acesso ao endividamento oneroso (significância de $10 \%$ ).

Em referência as dimensões de controle, destaque é dado para a rentabilidade e a liquidez, ambas negativamente relacionadas ao nível da dívida, tanto para com o endividamento total quanto para 0 endividamento oneroso. Visto os resultados da volatilidade do fluxo de caixa no nível da dívida, na sequência, mediante Tabela 3, têm-se os achados da volatilidade do fluxo de caixa na maturidade da dívida.

Tabela 3

Efeito da Volatilidade do Fluxo de Caixa na Estrutura de Capital - Maturidade da Dívida

\begin{tabular}{|c|c|c|c|c|c|c|}
\hline \multirow[t]{2}{*}{ Variáveis } & \multicolumn{3}{|c|}{$\begin{array}{l}\text { Endividamento de Longo } \\
\text { Prazo (ELP) }\end{array}$} & \multicolumn{3}{|c|}{$\begin{array}{c}\text { Endividamento Oneroso de Longo } \\
\text { Prazo (EOLP) }\end{array}$} \\
\hline & Coef. & t test & Sig. & Coef. & t test & Sig. \\
\hline VFC & $-0,3548$ & $-1,06$ & 0,289 & $-0,9944$ & $-2,55$ & $0,011^{* *}$ \\
\hline D_VFC & 0,0596 & 3,33 & $0,001^{*}$ & 0,0385 & 1,91 & $0,056^{\star * *}$ \\
\hline RENT & $-0,6571$ & $-5,64$ & $0,000^{*}$ & $-0,3633$ & $-2,39$ & $0,017^{* *}$ \\
\hline TAM & 0,0297 & 5,88 & $0,000^{*}$ & 0,0566 & 10,33 & $0,000^{*}$ \\
\hline LIQ & 0,0396 & 2,51 & $0,013^{* *}$ & 0,0592 & 3,37 & $0,001^{*}$ \\
\hline $\mathrm{CV}$ & 0,0382 & 0,66 & 0,510 & 0,0572 & 0,80 & 0,426 \\
\hline CONS & 0,0397 & 0,44 & 0,658 & $-0,2622$ & $-2,76$ & $0,006^{*}$ \\
\hline $\mathrm{R}^{2}$ & & 0,3596 & & & 40 & \\
\hline Sig. Modelo & & 0,0000 & & & 00 & \\
\hline Nr. Obs. & & 385 & & & & \\
\hline EF de Setor & & Sim & & & & \\
\hline EF de Ano & & Sim & & & & \\
\hline Jarque-Bera & & 0,0001 & & & 00 & \\
\hline VIF & & $\leq 1,70$ & & & 70 & \\
\hline Durbin-Watson & & 2,1233 & & & 37 & \\
\hline White Test & & 0,0000 & & & 00 & \\
\hline Matriz White (RR) & & Sim & & & & \\
\hline
\end{tabular}

Legenda: VFC = Volatilidade do Fluxo de Caixa; D_VFC = Dummy de tendência (inclinação) da Volatilidade do Fluxo de Caixa; RENT = Rentabilidade; TAM = Tamanho; $\mathrm{LIQ}$ = Liquidez; CV = Crescimento das Vendas; EF = Efeito Fixo; VIF = Variance Inflation Factor, RR = Regressão Robusta.

Nota: Significância ao nível de *1\%; ${ }^{* \star} 5 \%$; ${ }^{* * *} 10 \%$.

Fonte: Dados da pesquisa.

Os modelos vinculados a Tabela 3 também foram significativos ao nível de $1 \%$, o que permite inferências. Já o poder explicativo $\left(R^{2}\right)$ é de $35,96 \%$ e de $49,40 \%$ para com o endividamento de longo para (ELP) e o endividamento oneroso de longo prazo (EOLP), respectivamente. Ambos foram relaxados mediante teorema central do limite (normalidade), não contém problemas de multicolinearidade (VIF) e de autocorrelação (Durbin-Watson) e, ainda, foi aplicada regressão robusta a fim de corrigir a heterocedasticidade dos modelos.

Os resultados apontam que a volatilidade do fluxo de caixa esta negativamente relacionada com as dívidas contabilizadas no não circulante, todavia, é significativo apenas em relação ao endividamento oneroso de longo prazo. Ainda assim, tem-se que empresas com alta variação na geração de caixa possuem acesso mais restrito a dívidas com prazo de vencimento superior há um ano comparativamente a organizações com fluxos de caixa mais estáveis no decorrer do tempo. Além disso, a tendência do fluxo de caixa, medida pela variável D_VFC, aponta que quando as empresas estão alcançando melhores desempenhos de caixa nos últimos períodos, estas conseguem recursos de terceiros com prazos mais longos.

Por fim, relata-se que as variáveis de controle rentabilidade (negativa), tamanho (positiva) e liquidez 
(positiva) também se demonstraram como determinantes da maturidade da dívida das empresas industriais brasileiras aqui analisadas. Ademais, mediante Tabela 4, se apresenta os achados da volatilidade dos disponíveis de caixa (VDC) no nível de endividamento, sendo este foco de análise mais detalhada posteriormente.

\section{Tabela 4}

Efeito da Volatilidade da Disponibilidade de Caixa na Estrutura de Capital - Nível da Dívida

\begin{tabular}{|c|c|c|c|c|c|c|}
\hline \multirow[t]{2}{*}{ Variáveis } & \multicolumn{3}{|c|}{$\begin{array}{c}\text { Endividamento Total } \\
\text { (EndT) }\end{array}$} & \multicolumn{3}{|c|}{$\begin{array}{c}\text { Endividamento Oneroso } \\
\text { (EndO) }\end{array}$} \\
\hline & Coef. & t test & Sig. & Coef. & t test & Sig. \\
\hline VDC & 0,3288 & 0,96 & 0,338 & 1,3254 & 4,74 & $0,000^{*}$ \\
\hline D_VDC & 0,0175 & 0,74 & 0,460 & 0,0264 & 1,55 & 0,121 \\
\hline$\overline{\mathrm{RENT}}$ & $-0,7927$ & $-3,93$ & $0,000^{*}$ & $-0,3951$ & $-3,01$ & $0,003^{*}$ \\
\hline TAM & $-0,0167$ & $-2,96$ & $0,003^{*}$ & 0,0091 & 2,02 & $0,044^{* *}$ \\
\hline LIQ & $-0,1257$ & $-7,70$ & $0,000^{*}$ & $-0,0366$ & $-5,39$ & $0,000^{*}$ \\
\hline $\mathrm{CV}$ & 0,0121 & 0,16 & 0,871 & 0,1183 & 2,26 & $0,025^{* *}$ \\
\hline CONS & 1,1467 & 11,96 & $0,000^{*}$ & 0,2030 & 3,03 & $0,003^{*}$ \\
\hline $\mathrm{R}^{2}$ & \multicolumn{3}{|c|}{0,4191} & \multicolumn{3}{|c|}{0,2425} \\
\hline Sig. Modelo & \multicolumn{3}{|c|}{0,0000} & \multicolumn{3}{|c|}{0,0000} \\
\hline Nr. Obs. & \multicolumn{3}{|c|}{385} & \multicolumn{3}{|c|}{385} \\
\hline EF de Setor & \multicolumn{3}{|c|}{ Sim } & \multicolumn{3}{|c|}{ Sim } \\
\hline EF de Ano & \multicolumn{3}{|c|}{ Sim } & \multicolumn{3}{|c|}{ Sim } \\
\hline Jarque-Bera & \multicolumn{3}{|c|}{0,0000} & \multicolumn{3}{|c|}{0,0615} \\
\hline VIF & \multicolumn{3}{|c|}{$\leq 1,86$} & \multicolumn{3}{|c|}{$\leq 1,86$} \\
\hline Durbin-Watson & \multicolumn{3}{|c|}{2,0619} & \multicolumn{3}{|c|}{1,8775} \\
\hline White Test & \multicolumn{3}{|c|}{0,0000} & \multicolumn{3}{|c|}{0,0057} \\
\hline Matriz White (RR) & \multicolumn{3}{|c|}{ Sim } & \multicolumn{3}{|c|}{ Sim } \\
\hline
\end{tabular}

Legenda: VDC = Volatilidade da Disponibilidade de Caixa; D_VDC = Dummy de tendência (inclinação) da Volatilidade da Disponibilidade de Caixa; RENT = Rentabilidade; TAM = Tamanho; LIQ = Liquidez; CV = Crescimento das Vendas; $\mathrm{EF}=$ Efeito Fixo; VIF = Variance Inflation Factor; RR = Regressão Robusta.

Nota: Significância ao nível de *1\%; ${ }^{* \star} 5 \% ;{ }^{* * *} 10 \%$.

Fonte: Dados da pesquisa.

Os modelos aplicados na Tabela 4 têm como variáveis dependentes o endividamento total e o endividamento oneroso, que são explicados $\left(R^{2}\right)$ pelas variáveis independentes em 41,91\% e 24,25\%, respectivamente. Ambos os modelos são significativos em 1\%, garantindo suas aplicabilidades. Além disso, estabelecendo os pressupostos, tem-se a normalidade relaxada conforme teorema central do limite, o VIF apontando que não há problemas de multicolinearidade, o Durbin-Watson que não há problemas de autocorrelação e, ainda, foram operacionalizadas regressões robustas, visando corrigir problemas de heterocedasticidade.

Em face aos resultados, tem-se que a volatilidade da disponibilidade de caixa atua de forma positiva no nível de endividamento das empresas analisadas. Todavia, cabe destacar que o resultado mencionado é significativo apenas quando a variável dependente é o endividamento oneroso. Desta forma, afere-se que tanto a maior volatilidade do fluxo de caixa (Tabela 2) quanto a maior volatilidade da disponibilidade de caixa fazem com que as empresas busquem se financiar via terceiros de forma mais extensiva. Em contrapartida, apesar de positivos, os coeficientes de tendência da volatilidade da disponibilidade de caixa (D_VDC) não são significativos, não sendo esta variável, portanto, determinante do nível de endividamento nas empresas industriais brasileiras.

Já quanto as variáveis de controle, rentabilidade e liquidez se confirmam como negativamente relacionadas com os níveis de endividamento - total e oneroso. Além disso, o tamanho da empresa foi significativo em ambos, mas de forma negativa ao endividamento total e de forma positiva ao endividamento oneroso. O referido fator estabelece que empresas menores usufruam maior acesso a recursos de terceiros, mas tais recursos estão relacionados mais a aspectos operacionais - fornecedores, etc., visto que nas rubricas de empréstimos e financiamento e debêntures as organizações maiores apresentam níveis mais altos de dívidas. Por fim, mediante Tabela 5, apresentaram-se os resultados da volatilidade da disponibilidade de caixa na maturidade do endividamento das empresas.

A Tabela 5 demonstra que o poder explicativo $\left(R^{2}\right)$ dos modelos foi de $34,79 \%$ e $48,17 \%$, sendo o primeiro em função da variável dependente endividamento de longo prazo (ELP) e o segundo para com o endividamento oneroso de longo prazo (EOLP). Além disso, os dois modelos são significativos ao nível de $1 \%$, tendo a normalidade relaxada mediante teorema central do limite, não apresentando, conforme VIF e Durbin-Watson, respectivamente, problemas de multicolinearidade e autocorrelação e, ainda, tendo a heterogeneidade ajustada mediante a aplicação de regressão robusta que insere a matriz White. 
Tabela 5

Efeito da Volatilidade da Disponibilidade de Caixa na Estrutura de Capital - Maturidade da Dívida

\begin{tabular}{|c|c|c|c|c|c|c|}
\hline \multirow[t]{2}{*}{ Variáveis } & \multicolumn{3}{|c|}{$\begin{array}{c}\text { Endividamento de Longo } \\
\text { Prazo (ELP) }\end{array}$} & \multicolumn{3}{|c|}{$\begin{array}{c}\text { Endividamento Oneroso de Longo } \\
\text { Prazo (EOLP) }\end{array}$} \\
\hline & Coef. & t test & Sig. & Coef. & t test & Sig. \\
\hline VDC & $-0,4992$ & $-1,86$ & $0,063^{* * *}$ & 0,0208 & 0,07 & 0,941 \\
\hline D_VDC & 0,0164 & 0,92 & 0,357 & 0,00004 & 0,00 & 0,998 \\
\hline RENT & $-0,5318$ & $-4,87$ & $0,000^{*}$ & $-0,2621$ & $-1,77$ & $0,077^{* * *}$ \\
\hline TAM & 0,0336 & 7,47 & $0,000^{*}$ & 0,0612 & 12,68 & $0,000^{*}$ \\
\hline LIQ & 0,0401 & 2,55 & $0,011^{\star *}$ & 0,0650 & 3,66 & $0,000^{*}$ \\
\hline $\mathrm{CV}$ & 0,0560 & 0,96 & 0,339 & 0,0656 & 0,90 & 0,368 \\
\hline CONS & 0,0045 & 0,07 & 0,947 & $-0,3722$ & $-4,94$ & $0,000^{*}$ \\
\hline $\mathrm{R}^{2}$ & & 0,3479 & & & 0,4817 & \\
\hline Sig. Modelo & & 0,0000 & & & 0,0000 & \\
\hline Nr. Obs. & & 385 & & & 385 & \\
\hline EF de Setor & & Sim & & & Sim & \\
\hline EF de Ano & & Sim & & & Sim & \\
\hline Jarque-Bera & & 0,0000 & & & 0,0000 & \\
\hline VIF & & $\leq 1,86$ & & & $\leq 1,86$ & \\
\hline Durbin-Watson & & 1,9756 & & & 1,9759 & \\
\hline White Test & & 0,0000 & & & 0,0000 & \\
\hline Matriz White (RR) & & Sim & & & Sim & \\
\hline
\end{tabular}

Legenda: VDC = Volatilidade da Disponibilidade de Caixa; D_VDC = Dummy de tendência (inclinação) da Volatilidade da Disponibilidade de Caixa; RENT = Rentabilidade; TAM = Tamanho; LIQ = Liquidez; CV = Crescimento das Vendas; $\mathrm{EF}=$ Efeito Fixo; VIF = Variance Inflation Factor; RR = Regressão Robusta.

Nota: Significância ao nível de *1\%; ${ }^{* *} 5 \%$; ${ }^{* *} 10 \%$.

Fonte: Dados da pesquisa.

A variável volatilidade da disponibilidade de caixa, quando significativa, se apresenta negativamente relacionada à maturidade da dívida (especificamente ao endividamento de longo prazo). Logo, assim como no caso da volatilidade do fluxo de caixa (Tabela 3), a volatilidade da disponibilidade de caixa também é dada como minimizadora da obtenção de dívida de longo prazo por parte das empresas industriais brasileiras. Diferentemente, a tendência da disponibilidade de caixa, apesar de positiva, não apresenta significância com as medidas de maturidade da dívida e, assim, não é determinante do endividamento contabilizado no passivo não circulante. Finalmente, em face as variáveis de controle, rentabilidade (negativamente), tamanho (positivamente) e liquidez (positivamente) influenciam a maturidade da dívida.

\subsection{Discussão dos resultados}

Os resultados empíricos desta pesquisa proporcionam a discussão de inúmeros aspectos teóricos, desde sua aderência até posicionamentos diferenciados. Neste sentido, a volatilidade do fluxo de caixa apresentou relação positiva para com ambas às variáveis de nível de endividamento, sendo significativa com o endividamento total, o que vai de encontro aos preceitos teóricos existentes. De acordo com Keefe e Yaghoubi (2016) e Memon et al. (2018), a alta variabilidade do fluxo de caixa faz com que o custo da dívida se eleve conforme risco atrelado. Desta forma, com aumento das chances de embaraço financeiro ou insolvência, empresas com maior volatilidade do fluxo de caixa deveriam ser contrárias ao endividamento. Empiricamente, Martins e Vasconcelos (2020) observaram relação negativa entre volatilidade do fluxo de caixa e a estrutura de capital das empresas abertas brasileiras, classificando tal resultado como aderente à trade-off theory.

Todavia, contrastante ao achado empírico anterior, os resultados deste estudo sugerem que empresas industriais brasileiras com fluxos de caixa mais voláteis utilizam capital de terceiros em maior escala. Apesar de diferente do preconizado na literatura prévia consultada, tais evidências podem ser compreendidas como uma forma alternativa de captação de recursos que se deriva da insuficiência interna, em alguns períodos, que empresas com alta volatilidade do fluxo de caixa têm de se alto financiar. Logo, tais organizações arriscadas, visando dar continuidade em seus projetos, fazem uso mais extensivo de capital de terceiros, mesmo que isto possa significar aumento no custo de capital conforme mencionado por Keefe e Yaghoubi (2016) e Memon et al. (2018). Todavia, apesar de explicados, os resultados não suportam a hipótese 1 de pesquisa de que a volatilidade do fluxo de caixa tem efeito negativo no nível da dívida de empresas industriais brasileiras, rejeitando-a.

Ademais, quanto à tendência da volatilidade do fluxo de caixa no nível da dívida, observou-se que esta atua de forma positiva em ambas as medidas utilizadas, mas é significativa (a 10\%) somente no endividamento oneroso. Ao que pese, a volatilidade do fluxo de caixa pode se dar por variações descrentes ou crescentes. Para Ferreira e Vilela (2004), tanto disponibilidades quanto os fluxos de caixa abundantes atuam como minimizadores do custo de capital e de dificuldades financeiras para as empresas (Ferreira \& Vilela, 2004) e, desta forma, espera-se que o crescimento de ambos ao longo do tempo tenda a facilitar a 
captação de recursos via terceiros. Nesta perspectiva, os resultados aqui encontrados são complacentes com o preconizado na literatura prévia consultada.

Por sua vez, o efeito da volatilidade do fluxo de caixa na maturidade da dívida apresentou em ambas às variáveis dependentes coeficientes negativos, sendo significativa (a 5\%) com o endividamento oneroso de longo prazo. Este achado aponta que empresas com fluxos de caixa mais instáveis têm menor acesso a recursos de terceiros de longo prazo. A teoria de estrutura de capital trade-off defende que há um nível ótimo de endividamento que, de acordo com Miltersen e Toroso (2008), deve considerar, dentre outros fatores, os benefícios da flexibilidade do vencimento da dívida e os seus custos de emissão atrelados. Além disso, Keefe e Yaghoubi (2016) corroboram que o custo do endividamento tende a elevar-se conforme prazo superior de vencimento dos contratos firmados junto a terceiros.

Com base no exposto, é natural pressupor que empresas com alta volatilidade do fluxo de caixa, visando contrabalancear o custo do endividamento, reconhecidamente mais elevado para elas, buscam dívidas com prazo inferior, além de naturalmente terem maior dificuldade em estender prazos, uma vez que oferecem grau de risco superior aos credores. Com base nestes fatores, os achados desta pesquisa tornam-se concordantes com literatura anterior citada, permitindo não rejeitar a hipótese 3 de que a volatilidade do fluxo de caixa tem efeito negativo na maturidade da dívida de empresas industriais brasileiras.

Na sequência, observou-se que a tendência da volatilidade do fluxo de caixa atua de forma positiva tanto no endividamento de longo prazo (a 1\% de significância) como no endividamento oneroso de longo prazo (a 10\% de significância). De acordo com Dangl e Zechner (2016), a volatilidade do fluxo de caixa diminui o vencimento ótimo da dívida, todavia, a taxa de crescimento do referido fluxo tem efeito oposto. Assim, os achados desta pesquisa de que empresas com fluxos de caixas crescentes, mesmo que mais voláteis por conta disto, aumentam a busca e a contratação de dívidas com prazo superior de vencimento está de acordo com a literatura. Assim sendo, não se rejeita a hipótese 4 de que a tendência crescente do fluxo de caixa atenua o efeito negativo da volatilidade do fluxo de caixa na maturidade da dívida de empresas industriais brasileiras.

Os fluxos de caixa gerados são, em um primeiro momento, destinados como disponibilidades de caixa. Tais disponibilidades, mediante geração e posterior tomada de decisão dos gestores, podem sofrer maior ou menor variabilidade, afetando o nível e a maturidade da dívida das empresas. Neste sentido, observou-se que a volatilidade da disponibilidade de caixa é positivamente relacionada com o endividamento total e com o endividamento oneroso, sendo significante (a 1\%) com o último. Todavia, conforme Dang et al. (2012), empresas com desempenhos inconstantes tendem a possuir fluxos e disponibilidades de caixa voláteis, o que limita o acesso ao mercado financeiro. Logo, os resultados desta pesquisa divergem da teoria consultada, rejeitando-se a hipótese 5 de que a volatilidade da disponibilidade de caixa tem efeito negativo no nível da dívida de empresas industriais brasileiras.

Ademais, tem-se que a tendência da disponibilidade de caixa apresenta efeito positivo em ambas às medidas de nível da dívida, mas nenhuma delas é significativa. Como as disponibilidades de caixa podem ser vistas como potenciais aos pagamentos dos parcelamentos, Bhardwaj (2018) defende que o alto volume de folga financeira tende a tornar as empresas imunes a disciplina de mercado (Bhardwaj, 2018), sobretudo quanto existem limitações de acesso ao capital de terceiros. Logo, disponibilidades de caixa crescentes são entendidas como potencializadoras de acesso a recursos externos, estando em conformidade com o encontrado neste estudo. Porém, pela falta de significância, rejeita-se a hipótese 6 de que a tendência crescente da disponibilidade de caixa atenua o efeito negativo da volatilidade da disponibilidade de caixa no nível da dívida de empresas industriais brasileiras.

Quanto à volatilidade da disponibilidade de caixa em impactar a maturidade da dívida, tem-se que quando significativa (a 10\%), a referida variável afeta de forma negativa o endividamento de longo prazo. De acordo com Memon et al. (2018), no também cenário emergente da China, os fatores ligados a volatilidade do caixa proporcionam, além de níveis mais baixos de alavancagem as empresas, redução de aproximadamente $27 \%$ na probabilidade de emissão de dívidas de longo prazo, incluindo as debêntures. Os resultados significativos para o cenário brasileiro vão ao encontro com os preceitos teóricos e empíricos de Memon et al. (2018), não rejeitando a hipótese 7 que a volatilidade da disponibilidade de caixa tem efeito negativo na maturidade da dívida de empresas industriais brasileiras.

Por fim, a tendência da volatilidade do fluxo de caixa possui coeficiente positivo para com ambas as variáveis dependentes de maturidade da dívida, todavia, não são significativas. Conforme teoria, Bhardwaj (2018) defende que os padrões de mercado são minimizados quando a inclinação do caixa avança para a abundância de recursos (Bhardwaj, 2018). Logo, se a disponibilidade de caixa está variando devido ao crescimento do mesmo, o acesso ao capital de terceiros, inclusive de longo prazo, tende a ser facilitado. Desta forma, a relação positiva entre volatilidade da disponibilidade de caixa e a maturidade da dívida observada para o cenário brasileiro vão ao encontro da literatura prévia, todavia, ainda, assim, rejeita-se a hipótese 8 de pesquisa de que a tendência crescente da disponibilidade de caixa atenua o efeito negativo da volatilidade da disponibilidade de caixa na maturidade da dívida de empresas industriais brasileiras devido à falta de significância estatística. 


\section{Considerações Finais}

Este estudo teve por objetivo verificar o efeito da volatilidade do fluxo de caixa e da volatilidade da disponibilidade de caixa na estrutura de capital de empresas industriais brasileiras. Os resultados revelam que tanto a volatilidade do fluxo de caixa (VFC) como a volatilidade da disponibilidade de caixa (VDC) influenciam o nível e a maturidade da dívida das empresas, sendo a primeira de forma positiva e a segunda de forma negativa. Este fato sugere que, no contexto brasileiro, empresas com maior variabilidade de caixa-, ou seja, aquelas mais arriscadas, fazem uso mais extensivo de recursos de terceiros e, ainda, tais recursos são predominantemente de curto prazo.

Além disso, a variável de tendência da volatilidade do fluxo de caixa (D_VFC) aponta que quando a alta variação dos fluxos advém de uma tendência crescente de geração de caixa, as empresas apresentam maior facilidade em contrair dívidas junto a terceiros, bem como a contratar tais dívidas em prazo superior de tempo. Já a volatilidade da disponibilidade de caixa (D_VDC), apesar de também exibir coeficientes positivos, por não apresentar significância estatística, não é determinante do nível e da maturidade da dívida das empresas industriais brasileiras estudadas.

\subsection{Contribuições no Avanço do Conhecimento}

Os achados empíricos apontam que tanto à volatilidade do fluxo de caixa como a volatilidade da disponibilidade de caixa afetam positivamente o nível da dívida de empresas industriais brasileiras, diferindo dos preceitos prévios existentes acerca do fenômeno em questão, bem como de evidência empírica de Martins e Vasconcelos (2020) no Brasil. Logo, de posse destes resultados, é possível debater novas contribuições, bem como fornecer encaminhamentos para pesquisas futuras, sobretudo no cenário de estudo brasileiro.

Precisamente, legitima-se que a volatilidade dos aspectos ligados ao caixa - fluxo e disponibilidade - podem ser propulsores do endividamento corporativo, pois quando, durante alguns períodos, a geração interna de recursos se torna insuficiente para cobrir as demandas corporativas, o capital de terceiros passa a ser a principal fonte disponível de recursos e, portanto, utilizada pelos gestores corporativos, mesmo que isto possa significar o acréscimo dos riscos de dificuldades financeiras. Desta forma, contribui-se para que novos entendimentos sejam desenvolvidos, tomando por base o endividamento de terceiros como fonte alternativa de capitação de recursos por empresas em situações inconstantes de caixa.

Ademais, observou-se que a volatilidade do fluxo de caixa e da disponibilidade de caixa dificultam a captação de recursos de longo prazo junto a terceiros. Por mais que isto vá ao encontro do preconizado pela literatura prévia no que concerne exclusivamente a volatilidade dos aspectos ligados ao caixa para com a maturidade da dívida, quando analisados em conjunto com a volatilidade do caixa e o nível da dívida, trazem à tona uma situação ainda mais dificultosa para empresas brasileiras que apresentam fluxos de caixa com alta variabilidade.

Isto ocorre porque diferentemente da ordem teórica, que menciona tais empresas como menos endividadas (níveis) e com mais dívidas de curto prazo (maturidade), no cenário brasileiro desenha-se tais organizações como mais endividadas e, ainda, com dívidas majoritariamente no curto prazo, o que proporciona a pior condição possível para um devedor. Isto traz a necessidade de reflexões do quão prejudicial de fato é a volatilidade do fluxo e da disponibilidade de caixa às empresas. Ao que pese, os achados aqui evidenciados apontam a volatilidade dos aspectos ligados ao caixa com potencial ainda maior de asfixiar as finanças das empresas do que o já previamente pactuado na literatura da área.

Por fim, tem-se que a tendência da volatilidade do fluxo de caixa, que é ignorada em pesquisas anteriores, se demonstrou importante, quando apresenta inclinação crescente, para que empresas angariem mais recursos via terceiros e com prazos de vencimentos superiores há um ano (longo prazo). Logo, este estudo traz a reflexão que a direção da volatilidade deve ser avaliada em conjunto com o nível de variabilidade do fluxo de caixa. Todas as contribuições são de interesse de inúmeras partes, com especial atenção aos gestores, com vistas a qualificar a gestão dos recursos financeiros das empresas que administram.

\subsection{Limitações e Recomendações para Pesquisas Futuras}

Por mais que os resultados do estudo tragam novas perspectivas acerca do fenômeno observado, os mesmos devem ser interpretados com cautela, visto as limitações existentes e inerentes a pesquisas deste tipo. Tais limitações perpassam, sobretudo, por outras formas potenciais de dimensionar as variáveis de interesse, ainda mais que algumas das medidas utilizadas foram aplicadas de forma seminal sob a metodologia aqui adotada e, portanto, necessitam de novos insigths para se consolidarem. Logo, não é de interesse consumar o entendimento acerca do tema, mas justamente estabelecer novos e mais robustos parâmetros para pesquisas futuras.

Neste sentido, adotando a presente metodologia, pesquisadores podem explorar tais variáveis visando compreender o fenômeno em outros contextos, avançando, assim, tanto na aplicabilidade das 
medidas bem como na observância de potenciais diferenças que possam existir entre as inúmeras e diversificadas economias mundiais. Além disso, demais recortes metodológicos podem ser aplicados no cenário brasileiro, visto que o efeito da volatilidade do fluxo de caixa na estrutura de capital corporativa se demonstrou diferente nesta pesquisa comparativamente ao estudo de Martins e Vasconcelos (2020), apontando que a estratificação de amostras, a aplicação de modelos estatísticos mais completos, dentre outros fatores, pode trazer novos conhecimentos, ampliando e enriquecendo o debate acerca do tema.

\section{Referências}

Arslan, Ö., \& Karan, M. B. (2006). Ownership and control structure as determinants of corporate debt maturity: a panel study of an emerging market. Corporate Governance, 14(4), 312-324. https://doi.org/10.1111//.1467-8683.2006.00509.x

Baker, M., \& Wurgler, J. (2002). Market timing and capital structure. The Journal of Finance, 57(1), 1-32. https://doi.org/10.1111/1540-6261.00414

Bates, T. W., Kahle, K. M., \& Stulz, R. M. (2009). Why do U.S. firms hold so much more cash than they used to? The Journal of Finance, 64(5), 1985-2021. https://doi.org/10.1111/j.1540-6261.2009.01492.x

Benachenhou, A. (2013). Países emergentes (1. ed.). Brasília: Fundação Alexandre de Gusmão (FUNAG).

Bhardwaj, A. (2018). Financial leverage and firm's value: A study of capital structure of selected manufacturing sector firms in India. Tese de Doutorado, National Institute of Technology, Kurukshetra, Haryana, India.

Cai, K., Fairchild, R., \& Guney, Y. (2008). Debt maturity structure of chinese companies. Pacific-Basin Finance Journal, 16(3), 268-297. https://doi.org/10.1016/j.pacfin.2007.06.001

Chong, B-Uk., \& Kim, H. (2018). Capital structure volatility, financial vulnerability, and stock returns: Evidence from korean firms. Finance Research Letters, 30(1), 318-326. https://doi.org/10.1016/j.frl.2018.10.019

Couto, B. R. G. M., Oliveira, J. G. N. de, Torres, O. A., \& Morais, R. C. de. (2015). Estatística e probabilidades (1. ed.). Belo Horizonte: Grupo Ãnima Educação.

Dang, V. A., Kim, M., \& Shin, Y. (2012). Asymmetric capital structure adjustments: New evidence from dynamic panel threshold models. Journal of Empirical Finance, 19(4), 465-482. https://doi.org/10.1016/i.jempfin.2012.04.004

Dangl, T., \& Zechner, J. (2016). Debt maturity and the dynamics of leverage. Center for Financial Studies (CFS) Working Paper Series $n^{\circ}$ 547, Frankfurt, Germany.

Fávero, L. P., Belfiore, P., Silva, F. L., \& Chan, B. L. (2009). Análise de Dados: Modelagem Multivariada para Tomada de Decisões (2. ed.). Rio de Janeiro: Elsevier.

Ferreira, M. A., \& Vilela, A. S. (2004). Why do firms hold cash? Evidence from EMU countries. European Financial Management, 10(2), 295-319. https://doi.org/10.1111/i.1354-7798.2004.00251.x

Freund, J. E., \& Simon, G. A. (2000). Estatística aplicada: Economia, administração e contabilidade (9. ed.). Porto Alegre: Bookman.

Keefe, M. O'C., \& Yaghoubi, M. (2016). The influence of cash flow volatility on capital structure and de use of debt of different maturities. Journal of Corporate Finance, 38(1), 18-36. https://doi.org/10.1016/i.jcorpfin.2016.03.001

Leland, H. E., \& Toft, K. B. (1996). Optimal capital structure, endogenous bankruptcy, and the term structure of credit spreads. The Journal of Finance, 51(3), 987-1018. https://doi.org/10.1111/j.1540$\underline{6261.1996 . t b 02714 . x}$

Martins, R. K. B., \& Vasconcelos, L. N. C. de. (2020). Volatilidade dos fluxos de caixa e a estrutura de capital das empresas abertas brasileiras. Sociedade, Contabilidade e Gestão, 15(3), 1-21. 
Memon, Z., Chen, Y., Tauni, M. Z., \& Ali, H. (2018). The impact of cash flow volatility on firm leverage and debt maturity structure: Evidence from China. China Finance Review International, 8(1), 69-81. https://doi.org/10.1108/CFRI-06-2017-0106

Miltersen, K. R., \& Torous, W. N. (2008). Risky corporate debt with finite maturity. SSRN Electronic Journal, 1-46. https://doi.org/10.2139/ssrn.1315366

Modigliani, F., \& Miller, M. H. (1958). The cost of capital, corporation finance and the theory of investment. The American Economic Review, 53(3), p. 261-297.

Modigliani, F., \& Miller, M. H. (1963). Corporate income taxes and the cost of capital: a correction. The American Economic Review, 53(3), p. 433-443.

Mouton, M., \& Smith, N. (2016). Company determinants of capital structure on the JSE Ltd and the influence of the 2008 financial crisis. Journal of Economic and Financial Sciences, 9(3), 789-806. https://doi.org/10.4102/jef.v9i3.71

Muritala, T. A. (2012). An empirical analysis of capital structure on firms' performance in Nigeria. International Journal of Advances in Management and Economics, 1(5), 116-124.

Myers, S. C. (1984). The capital structure puzzle. The Journal of Finance, 39(3), 575-592. https://doi.org/10.3386/w1393

Serrasqueiro, Z., \& Caetano, A. (2015). Trade-off theory versus pecking order theory: Capital structure decisions in a peripheral region of Portugal. Journal of Business Economics and Management, 16(2), 445466. https://doi.org/10.3846/16111699.2012.744344

Tripathy, N., \& Asija, A. (2017). The impact of financial crisis on the determinants of capital structure of listed firms in India. J. of International Business and Economy, 18(1), 101-121.

Veirman, E. de, \& Levin, A. (2018). Cyclical changes in firm volatility. Journal of Money, Credit and Baking, 50(2-3), 317-349. https://doi.org/10.1111/imcb.12462

Yaghoubi, M. (2017). Three essays on capital structure. Tese de Doutorado, Victoria University, Welligton, Australia.

*Versão preprint do artigo foi apresentada na XIX International Finance Conference, 2019.

\section{NOTAS}

\section{AGRADECIMENTOS}

Os autores agradecem aos avaliadores da XIX International Finance Conference e da Revista Contemporânea de Contabilidade pelas considerações realizadas, que possibilitaram uma série de melhorias ao artigo.

\section{CONTRIBUIÇÃO DE AUTORIA}

Concepção e elaboração do manuscrito: E. Pamplona, C. Canton, T. P. da Silva, M. M. Rodrigues Junior Coleta de dados: E. Pamplona

Análise de dados: E. Pamplona

Discussão dos resultados: E. Pamplona, C. Canton, T. P. da Silva, M. M. Rodrigues Junior

Revisão e aprovação: E. Pamplona

\section{CONJUNTO DE DADOS DE PESQUISA}

O conjunto de dados que dá suporte aos resultados deste estudo não está disponível publicamente.

\section{FINANCIAMENTO}

Não se aplica.

\section{CONSENTIMENTO DE USO DE IMAGEM}

Não se aplica. 


\section{APROVAÇÃO DE COMITÊ DE ÉTICA EM PESQUISA}

Não se aplica.

\section{CONFLITO DE INTERESSES}

Não se aplica.

\section{LICENÇA DE USO}

Os Direitos Autorais para artigos publicados neste periódico são do autor, com direitos de primeira publicação para a Revista. Em virtude de aparecerem nesta Revista de acesso público, os artigos são de uso gratuito, com atribuições próprias, em aplicações educacionais, de exercício profissional e para gestão pública. A Revista adotou a licença Creative Commons Atribuição 4.0 Internacional - CC BY NC ND. Esta licença permite acessar, baixar (download), copiar, imprimir, compartilhar, reutilizar e distribuir os artigos desde que com a citação da fonte, atribuindo os devidos créditos de autoria. Nesses casos, nenhuma permissão é necessária por parte dos autores ou dos editores. Autores têm autorização para assumir contratos adicionais separadamente, para distribuição não-exclusiva da versão do trabalho publicada nesta revista (ex.: publicar em repositório institucional ou um capítulo de livro).

\section{PUBLISHER}

Universidade Federal de Santa Catarina. Curso de Ciências Contábeis e Programa de Pós-graduação em Contabilidade. Publicação no Portal de Periódicos UFSC. As ideias expressadas neste artigo são de responsabilidade de seus autores, não representando, necessariamente, a opinião dos editores ou da universidade.

\section{EDITORES}

Carlos Eduardo Facin Lavarda e Suliani Rover

\section{HISTÓRICO}

Recebido em: 03/11/2020 - Revisado por pares em: 12/05/2021 - Reformulado em: 30/07/2021 Recomendado para publicação em: 02/08/2021 - Publicado em: 04/12/2021 